\title{
Point-of-sale cigarette marketing and smoking-induced deprivation in smokers: results from a population-based survey
}

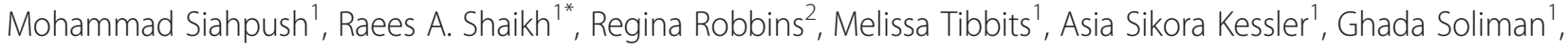
Molly McCarthy ${ }^{1}$ and Gopal K. Singh ${ }^{3}$

\begin{abstract}
Background: Strict restrictions on outdoor cigarette marketing have resulted in increasing concentration of cigarette marketing at the point-of-sale (POS). The association between POS cigarette marketing and smoking-induced deprivation (SID) has never been studied. The aim of this study was to examine this association and how it is mediated by cravings to smoke, urges to buy cigarettes, and unplanned purchases of cigarettes.

Methods: Data from a telephone survey of 939 smokers were collected in Omaha, Nebraska. POS cigarette marketing was measured by asking respondents three questions about noticing pack displays, advertisements, and promotions such as cigarette price discounts within their respective neighborhoods. SID was measured with the following question: "In the last six months, has there been a time when the money you spent on cigarettes resulted in not having enough money for household essentials such as food? [yes/no]" We used structural equation modeling to examine the study aim.

Results: There was overwhelming evidence for an association between higher levels of POS cigarette marketing and a higher probability of SID $(p<0.001)$. This association was partly mediated by cravings to smoke, urges to buy cigarettes, and unplanned purchases of cigarettes during a visit to a neighborhood store $(p<0.001)$.

Conclusion: Given that POS cigarette marketing is associated with a higher probability of experiencing SID, policies that ban POS cigarette marketing might help some smokers afford essentials household items such as food more easily and thus have better standards of living.
\end{abstract}

Keywords: Point-of-sale tobacco marketing, Smoking-induced deprivation, Cravings to smoke, Urge to buy cigarettes, Unplanned purchase of cigarettes

\section{Background}

As a result of the 1998 Master Settlement Agreement in the United States, a legal settlement that eliminated most forms of outdoor cigarette advertising such as on billboards, cigarette marketing has increasingly concentrated at the point of sale (POS) [1-3]. In 2011, about $89 \%$ of the $\$ 8.4$ billion of tobacco industry expenditures for cigarette marketing was made at the POS [4] in the following three areas: cigarette pack displays, advertisements, and price incentives to consumers [2-4].

\footnotetext{
* Correspondence: raees.shaikh@unmc.edu

'University of Nebraska Medical Center, 984365 Nebraska Medical Center,

Omaha, NE 68198-4365, USA

Full list of author information is available at the end of the article
}

POS cigarette marketing can act as a cue to smoke and promote cravings to smoke, urges to buy cigarettes, and impulse or unplanned purchases of cigarettes [5-14]. In an experimental study of 1216 current smokers and recent quitters, Kim et al. reported that exposure to an enclosed (invisible) display compared to an open display of cigarette packs in a virtual store resulted in a lower level of selfrated craving [5]. In a different experimental study of 63 smokers, Carter et al. found that self-rated craving to smoke was higher following exposure to a photo of eight cigarette packs than exposure to a neutral photo with no cigarette imagery [6]. Observational studies also indicate an association between exposure to pack displays and cravings to smoke. In a qualitative study, Hoek et al. conducted semi-structured in-depth interviews 
with 20 participants who had attempted to quit smoking in the previous six months [7]. Many participants indicated that seeing cigarette displays reminded them of smoking and promoted not only cravings but also impulse purchases of cigarettes. Similarly, in a cross-sectional study of 526 current smokers, Wakefield et al. found that the frequency of noticing cigarette displays was positively related to the probability of getting an urge to buy cigarettes and making an impulse purchase of cigarettes [8]. Similar findings were reported by Carter et al. who conducted intercept interviews with 206 smokers who were observed purchasing cigarettes from retail outlets and found that POS displays were associated with four times as many unplanned purchases as purchases that were planned [9]. About $22 \%$ of the participants in Carter et al.'s study reported that they did not plan to purchase cigarettes before entering the store and $20 \%$ indicated that cigarette pack displays encouraged them to purchase cigarettes in that instance. Finally, two other observational studies using the same sample of 999 smokers reported that POS displays and advertisements were associate with more frequent cravings to smoke [14] and that POS marketing (a summated scale consisting of items about exposure to POS displays, advertisement, and promotions) was associated with more frequent urges to buy and impulse purchases of cigarettes [13]. In the field of public health, the phrases "unplanned purchase" and "impulse purchase" have been used interchangeably. However, marketing literature makes a clear distinction between these two phrases. Based on this literature, while an unplanned purchase refers to a shopping decision made without any advanced planning, an impulse purchase refers to a shopping decision that in addition to being unplanned, involves a sudden, strong, and often irresistible urge to purchase $[15,16]$.

An area of research that has not previously been explored is the extent to which POS marketing and its immediate consequences such as stimulating cravings to smoke, urges to buy cigarettes, and unplanned purchases of cigarettes, can contribute to the deleterious effects of smoking on the standards of living of smokers. Research shows that spending money on cigarettes and smoking can diminish financial and material well-being [17-22]. In a cross-sectional study of 6,892 households, Siahpush et al. found that spending money on cigarettes was associated with an increased probability of experiencing financial stress (e.g. going without meals or not being able to pay rent due to shortage of money) and that among households with a smoker, spending more on tobacco was associated with a higher probability of financial stress [18]. In a different study of 5887 smokers, Siahpush et al. directly measured "smoking-induced deprivation" (SID) by asking respondents whether there was an instance in recent times where spending money on cigarettes resulted in not having enough money for necessities of life such as food [21] and found that those who spent more money on cigarettes were more likely to experience SID. This finding was replicated in a different cross-sectional study of 2,410 smokers [17].

While the association of POS cigarette marketing with cravings to smoke, urges to buy cigarettes, and unplanned purchases of cigarettes, on the one hand, and the association of smoking behavior with smokinginduced deprivation (SID), on the other hand, have been examined in previous literature, there are no studies that link these concepts together to investigate the relationship between POS cigarette marketing and SID. Based on the studies described above, we posited a conceptual framework depicted in Fig. 1. This model indicates that POS cigarette marketing can lead to cravings to smoke and urges to buy cigarettes during a visit to a store, which in turn can lead to unplanned purchases of cigarettes. Unplanned purchases of cigarettes can thus result in SID. We have also explored a direct effect of POS cigarette marketing on SID. Our aim was to use structural equation modelling to examine the relationship between POS cigarette marketing and SID and investigate how this relationship is mediated by cravings to smoke, urges to buy cigarettes, and unplanned purchases of cigarettes in a

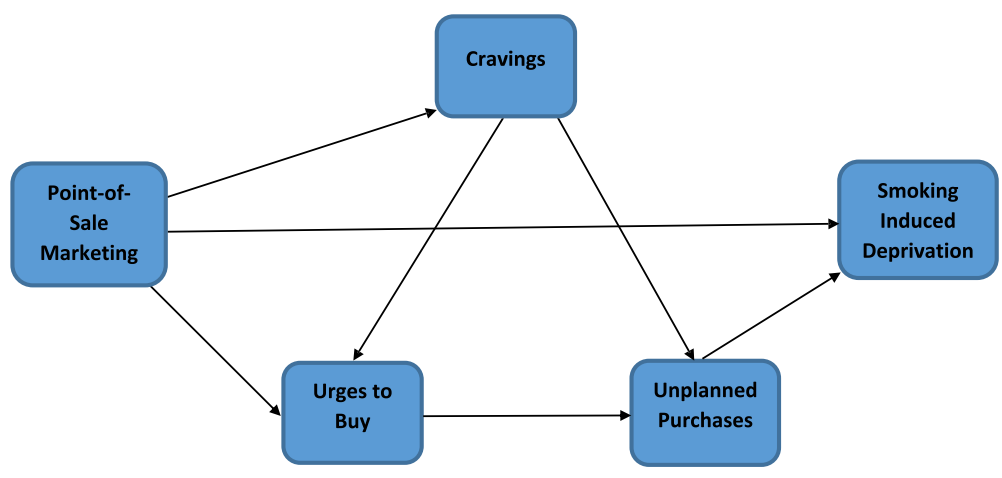

Fig. 1 Hypothesized path model linking POS cigarette marketing to SID 
cross-sectional, population-based sample of smokers in Omaha, Nebraska.

\section{Methods \\ Sample}

A total of 999 adult respondents were recruited in Omaha, Nebraska, using random digit dialing (47.2\% with a response rate of $22.4 \%$ ) and placement of local advertisements (52.8 \%) in media such as the major daily newspaper and Craigslist, in 2014. All data were collected using telephone interviews that took an average of $20 \mathrm{~min}$. Those included in the study spoke English, were 18 years of age or older, were current smokers meaning that they had smoked more than 100 cigarettes in their life, [23] and smoked five or more cigarettes a day at the time of recruitment. We excluded very light smokers, i.e. current smokers who smoked less than 5 cigarettes a day, because they appear to be notably different from other smokers in relation to important smoking-related factors such as tobacco dependence, cravings to smoke before or after smoking cessation, [24] likelihood to make a quit attempt, post-cessation withdrawal symptoms, [25] and smoking motives [26]. Those who responded "never" to the following question were excluded from the study: "How often do you visit the stores in the neighborhood where you live? By stores, we mean such places as convenience stores, gas stations, grocery stores, supermarkets, drug stores, liquor stores, and tobacco stores." Response options were $1=$ never, 2 = sometimes, $3=$ frequently, and $4=$ always. The University of Nebraska Medical Center Institutional Review Board provided ethics approval for the study. Informed consent was obtained from each participant verbally as the data collection was done through telephone interviews.

While the study sample was not a random sample, its socio-demographic distribution was similar to the subsample of smokers in the center city of Nebraska Metropolitan Statistical Areas in the Behavioral Risk Factor Surveillance System (BRFSS) [27]. For example, the gender distribution in our sample and BRFSS were identical. The mean age was 47.8 years in our sample and 53 years in BRFSS. The percentage of Whites was 71.7 in our sample and 86.1 in BRFSS. The percentage of respondents with a high school diploma or a lower level of education was 49.9 in our sample and 46.3 in BRFSS. The median income was $\$ 22,500$ in our sample and $\$ 30,000$ in BRFSS.

\section{Measurement}

\section{Latent variables}

We measured exposure to POS marketing with the following three survey items, which are adapted from previous studies: $[8,28]$ "When you are in a store in your neighborhood, how often do you notice tobacco ads?"; "When you are in a store in your neighborhood, how often do you notice tobacco promotions such as special prices, multi-pack discounts, or free gift with purchase of cigarettes?"; and "When you are in a store in your neighborhood, how often do you notice cigarette pack displays?" Possible responses to each question were: $1=$ never, $2=$ rarely, $3=$ sometimes, $4=$ often, $5=$ always. Before asking these questions, respondents were told that in the study "store" refers to convenience store, gas station, grocery store, supermarket, drug store, liquor store, tobacco store, etc. where tobacco products are sold.

We measured cravings to smoke with the following three survey items: "When you are in a store in your neighborhood that sells tobacco products, how often do you (1) feel a craving for a cigarette? (2) feel like nothing would be better than smoking a cigarette? (3) feel like all you want is a cigarette?". The response options were: $1=$ never, $2=$ rarely, $3=$ sometimes, $4=$ often, $5=$ always [29-32].

\section{Observed variables}

SID was measured with the following question: "In the last six months, has there been a time when the money you spent on cigarettes resulted in not having enough money for household essentials such as food?" [17, 21, 33].

We measured urges to buy cigarettes and unplanned purchases of cigarettes using the following two questions, respectively, which were adapted from previous studies: $[8,28]$ : "When you are in a store in your neighborhood, how often do you get an urge to buy cigarettes?"; and "When you are in a store in your neighborhood to shop for something other than cigarettes, how often do you decide to buy cigarettes?" Possible response options were: $1=$ never, $2=$ rarely, $3=$ sometimes, $4=$ often, $5=$ always.

We included the following control variables in the analyses: Heaviness of Smoking Index (HSI), which is an indicator of nicotine dependence, [34, 35] gender, age in years, race/ethnicity, household income, education, frequency of visiting stores, and method of recruitment (random digit dialing versus other). Race was categorized as non-Hispanic White, non-Hispanic Black, Hispanic, and other. Education was categorized based on highest grade or year of school completed as follows: less than high school, high school graduate, some college, and college graduate and higher.

\section{Statistical analysis}

We used Stata v. 13 for descriptive statistics [36] and Mplus [37] to perform structural equation modeling (SEM) to address the aim of the study. SEM is a multivariate technique that estimates parameters in structural equations in order to simultaneously examine complex relationships between several independent and dependent 
variables and estimate direct, indirect, and total effects. SEM can accommodate latent variables with multiple indicators to isolate and remove measurement error and enhance predictive power [38]. Observations that had a missing value on any of the study variables, which constituted $6 \%$ of the original sample, were omitted from the analysis. The analysis sample size was 939 . We examined the association of missingness with sociodemographic factors and the study outcome. There was very little evidence that missingness was associated with gender ( $n=999 ; p=0.669)$, race/ethnicity $(n=996 ; p=0.057)$, education $(n=998 ; p=0.769)$, or $\operatorname{SID}(n=998 ; p=0.054)$. However, there was evidence that the mean age of the individuals in the analysis was lower than that of those not included in the analysis ( $n=994 ; p=0.003)$.

We performed SEM in two stages [39]. First, using maximum likelihood parameter estimation with standard errors and mean- and variance-adjusted (MLMV) chisquare test statistics for continuous data, [37] we estimated a measurement model involving POS cigarette marketing and cravings to smoke, each with three indicators. Next, using probit regression and robust weighted least square parameter estimation with standard errors and mean- and variance-adjusted (WLSMV) chi-square test statistic for binary outcome, [37] we estimated a structural model representing both latent (POS marketing and cravings to smoke) and observed variables of interest (urge to buy cigarettes, unplanned purchase of cigarettes, and SID) in the study and specifying the pathways connecting these variables [37]. Where appropriate, we used the modification index to estimate additional parameters to enhance the fit of a model. We used the DIFFTEST procedure, which provides a $X^{2}$ difference test, to compare nested models. We included all of the control variables as exogenous observed variables in structural equations. If the $p$-value for the effect of a control variable was greater or equal to 0.05 in any of the equations, it was removed from that equation. We used comparative fit index (CFI), Tucker-Lewis index (TLI), and root mean square error of approximation (RMSEA) to assess the fit of the models. A model was considered to have a good fit with the observed data if the following were true: CFI $>=0.95$, TLI $>=0.95$, and RMSEA $<=0.05[40,41]$. Standardized coefficients representing the direct effects were presented in the structural equation diagram. Standardized coefficients are expressed in terms of standard deviation units and as such provide a measures of the strength of association, are used as an effect size index, and allow a comparison of different effects within the same model [42]. Estimates of total and indirect effects (Muthén B: Applications of causally defined direct and indirect effects in mediation analysis using SEM in Mplus, unpublished working paper) of POS on SID were also provided. All reported coefficients are standardized regression coefficients or $\beta$ s. It should be noted that, as is customary in describing the results of SEM, we use the word "effect" to describe the association between variables rather than to ascribe a causal nature to the observed pattern of associations.

\section{Results}

\section{Sample characteristics}

Table 1 shows the characteristics of the sample. Eleven and a half percent of respondents reported having experienced SID in the past six months. The mean of exposure to POS

Table 1 Sample characteristics $(n=939)$

\begin{tabular}{|c|c|}
\hline Variables & $\%$ or mean (range, standard deviation) \\
\hline \multicolumn{2}{|l|}{ SID } \\
\hline Yes & 11.5 \\
\hline No & 88.5 \\
\hline \multicolumn{2}{|l|}{ POS marketing } \\
\hline Displays & $3.11(1.48)$ \\
\hline Ads & $3.13(1.55)$ \\
\hline Promotions & $2.79(1.33)$ \\
\hline \multicolumn{2}{|l|}{ Cravings } \\
\hline Craving for a cigarette & $2.75(1.34)$ \\
\hline Nothing better than a cigarette & $2.76(1.24)$ \\
\hline All you want is a cigarette & $2.94(1.15)$ \\
\hline Urges to buy cigarettes & $3.02(1.31)$ \\
\hline Unplanned purchases & $2.58(1.2)$ \\
\hline $\mathrm{HSI}$ & $3.27(0.92)$ \\
\hline \multicolumn{2}{|l|}{ Sex } \\
\hline Male & 57.19 \\
\hline Female & 42.81 \\
\hline Age & $47.5(14.23)$ \\
\hline \multicolumn{2}{|l|}{ Race/ethnicity } \\
\hline Non-Hispanic White & 65.81 \\
\hline Non-Hispanic Black & 24.17 \\
\hline Hispanic & 3.09 \\
\hline Other & 6.92 \\
\hline Income $(\$ 1000)$ & $31.08(23.23)$ \\
\hline \multicolumn{2}{|l|}{ Education } \\
\hline Less than high school & 10.12 \\
\hline High school graduate & 39.83 \\
\hline Some college & 36.95 \\
\hline \multicolumn{2}{|l|}{ Frequency of visits to stores } \\
\hline Sometimes & 11.50 \\
\hline Frequently & 36.85 \\
\hline Always & 51.65 \\
\hline \multicolumn{2}{|l|}{ Method of recruitment } \\
\hline Random digit dialing & 45.26 \\
\hline Other & 54.74 \\
\hline
\end{tabular}


cigarette marketing was 3.1 (SD: 1.5) for displays, 3.1 (SD: 1.6) for advertisements, and 2.8 (SD: 1.3) for promotions. The means of feeling a craving for a cigarette, that nothing would be better than a cigarette, and that all that is wanted is a cigarette were 2.8 (SD: 1.3), 2.8 (SD: 1.2), and 2.9 (SD: $1.2)$, respectively. The mean of urge to buy cigarettes and unplanned purchase of cigarettes were 3 (SD: 1.3) and 2.6 (SD: 1.2), respectively. The mean level of HSI was 3.3 (SD: 0.9). The percentage of men was 57.2. Mean age was 47.5 (SD: 14.2). Respondents who were non-Hispanic White, non-Hispanic Black, and Hispanic comprised $65.8 \%$, $24.2 \%$ and $3.1 \%$ of the sample, respectively. Mean income was $\$ 31,000$ (SD: $\$ 23,230$ ) and $49.9 \%$ of the sample had finished high school or had a lower level of education. The percentage of respondents who visited the stores in their neighborhoods sometimes, frequently, or always, was 11.5, 36.8, and 51.6, respectively. About $45.3 \%$ of the analysis sample were recruited by random digit dialing.

\section{Measurement model}

The measurement model with POS cigarette marketing and cravings to smoke as latent variables provided good fit to the data $(C F I=0.98$; TLI $=0.96$; $\mathrm{RMSEA}=0.06$ ). An examination of the modification indices indicated that adding a parameter for a correlation between the error terms of two of the indicators of cravings to smoke, namely "feel like nothing would be better than smoking a cigarette" and "feel like all you want is a cigarette", would further enhance the fit of the model.
Data provided support for adding this parameter $\left(\chi^{2}\right.$ for difference: 22.36, $1 \mathrm{df}, p<0.001)$ and the indices of fit improved $(\mathrm{CFI}=1 ; \mathrm{TLI}=0.99 ; \mathrm{RMSEA}=0.03)$. In this revised measurement model, the $p$-values for all the loadings (standardized coefficients) were smaller than 0.001 .

\section{Structural model}

The path diagram depicted in Fig. 1, which represents the conceptual framework of the study, was further refined to include the measurement model, as shown in Fig. 2. In this figure, ovals represent latent variables and rectangles represent observed variables. For simplicity of presentation, control variables are not included in the diagram. The model provided a good fit to the data $(\mathrm{CFI}=0.97$; $\mathrm{TLI}=0.96$; RMSEA $=0.02$ ). As indicated by the $p$-values associated with each path, there was overwhelming evidence that POS cigarette marketing was associated with cravings to smoke, urges to buy cigarettes, and SID; cravings to smoke was associated with urges to buy cigarettes and unplanned purchases of cigarettes; urges to buy cigarettes were associated with unplanned purchases of cigarettes; and unplanned purchases of cigarettes were associated with SID. All of these relationships were positive, showing that higher levels of POS marketing and unplanned purchases of cigarettes were associated with a higher probability of SID. Examining the magnitude of the unstandardized coefficient in Fig. 2 indicates the following: the direct effect of cravings to smoke on urges to buy cigarettes was notably greater than the direct effect of POS marketing on urges to buy cigarettes; the direct effect of

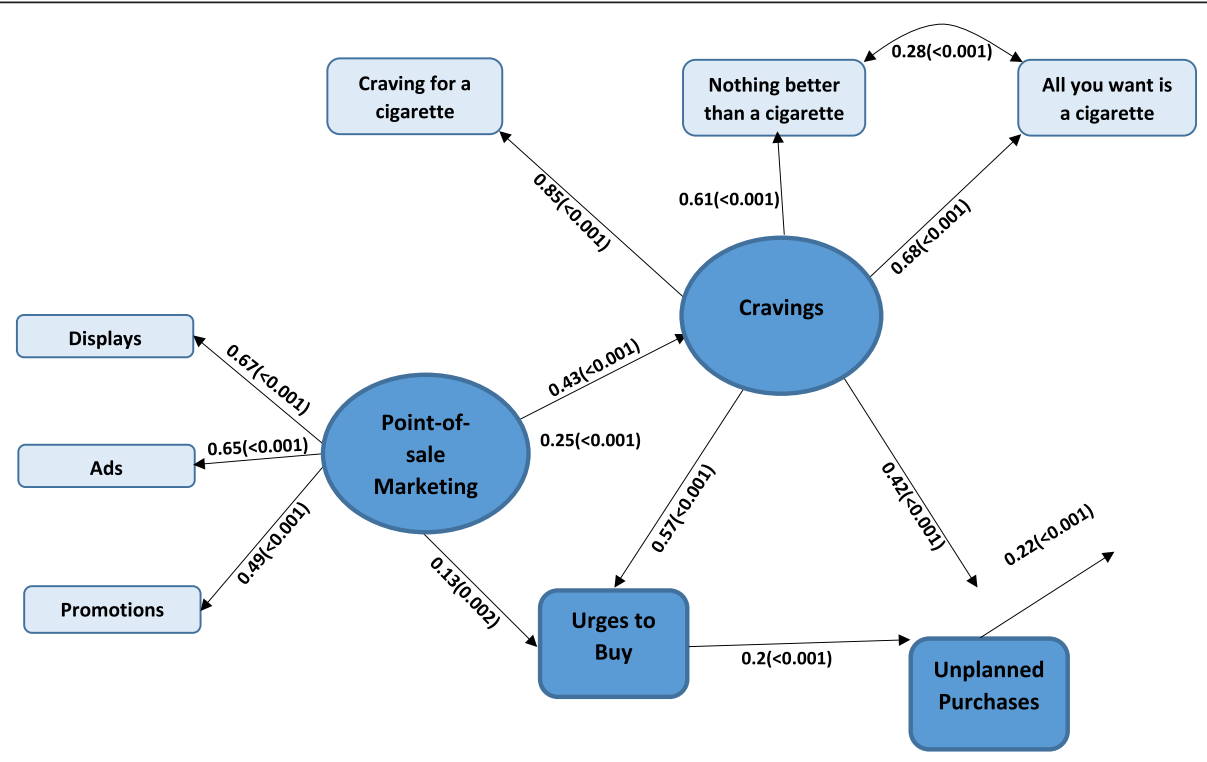

Note: Rectangles represent observed variables and ovals represent latent variables. All numbers outside parentheses are standardized coefficients. Numbers corresponding to error terms are error variances. Numbers in parentheses are $p$-values.

Fig. 2 Structural equation model for the relationship between POS cigarette marketing and smoking-induced deprivation (SID) 
cravings to smoke on unplanned purchases of cigarettes was notably larger than the direct effect of urges to buy cigarettes on unplanned purchases of cigarettes; and the direct effect of POS marketing on SID was very similar to the direct effect of unplanned purchases of cigarettes on SID.

Table 2 shows the effect of control variables on the endogenous variables. None of the control variables were associated with urges to buy cigarettes. Females, older respondents, and Whites (compared to other races or ethnic groups) were exposed to lower levels of POS marketing. Having a lower HSI level, being male, being older, and having a higher level of income or education were associated with a lower frequency of cravings to smoke. Compared to other race/ethnicities, Whites reported a lower frequency of unplanned purchases of cigarettes. Respondents with a higher level of HSI, and those who were nonHispanic White (compared to other race/ethnicities) had a higher probability of SID.

Table 3 shows the total, direct, and indirect effects of POS marketing on SID. The direct effect accounted for $81.6 \%$ and the total indirect effect accounted for $18.4 \%$ of the total effect of POS cigarette marketing on SID. While the data supported all three indirect effects, most of the total indirect effect was via cravings to smoke and unplanned purchases of cigarettes.

\section{Discussion}

In this study, we used SEM to investigate the previouslyunexplored relationship between exposure to POS cigarette marketing and SID. We found strong evidence that POS cigarette marketing is associated with SID and that part of this association was mediated by cravings to smoke, urges to buy cigarettes, and unplanned purchases of cigarettes during a visit to a store.

The experience of SID and other forms of financial deprivation that result from smoking [43-46] are important not only because they indicate compromised standards of living, but also because they can lead to further unfavorable smoking behaviors and outcomes. For example, smokers who experience SID are less likely to attempt to quit smoking and those who do try to quit are more likely to relapse [43]. Similarly, smokers who experience financial stress are less likely to quit and ex-smokers who experience financial stress are more likely to relapse $[45,46]$. In short, the relationship between financial deprivation and smoking is reciprocal and smokers are often caught in a vicious cycle of experiencing financial deprivation because of smoking and

Table 2 Adjusted standardized coefficients and p-values (in parentheses) for the effect of control variables on POS marketing, cravings to smoke, unplanned purchases of cigarettes, and SID $(n=939)$

\begin{tabular}{|c|c|c|c|c|}
\hline Control variables & POS marketing & Cravings to smoke & Unplanned purchases & SID \\
\hline $\mathrm{HSI}$ & - & $0.14(<0.001)$ & - & $0.11(0.033)$ \\
\hline \multicolumn{5}{|l|}{ Sex } \\
\hline Male & $0.13(<0.001)$ & $-0.11(0.001)$ & - & - \\
\hline Female & 0 & 0 & - & - \\
\hline Age & $-0.024(<0.001)$ & $-0.09(0.018)$ & - & - \\
\hline \multicolumn{5}{|l|}{ Race/ethnicity } \\
\hline Non-Hispanic White & 0 & - & 0 & 0 \\
\hline Non-Hispanic Black & $0.11(0.008)$ & - & $0.09(0.005)$ & $-0.14(0.016)$ \\
\hline Hispanic & $0.08(0.022)$ & - & $0.04(0.126)$ & $-0.04(0.393)$ \\
\hline Other & $0.03(0.459)$ & - & $0.02(0.418)$ & $0.05(0.238)$ \\
\hline Income $(\$ 1000)$ & $0.13(0.002)$ & $-.10(0.015)$ & - & $-0.42(<0.001)$ \\
\hline \multicolumn{5}{|l|}{ Education } \\
\hline Less than high school & - & 0 & - & - \\
\hline High school graduate & - & $-0.12(0.034)$ & - & - \\
\hline Some college & - & $-0.19(0.001)$ & - & - \\
\hline \multicolumn{5}{|c|}{ Frequency of visits to stores } \\
\hline Sometimes & 0 & 0 & - & - \\
\hline Frequently & $0.16(0.016)$ & $0.13(0.026)$ & - & - \\
\hline Always & $0.28(<0.00)$ & $0.14(0.013)$ & - & - \\
\hline \multicolumn{5}{|l|}{ Method of recruitment } \\
\hline Random digit dialing & $-0.15(<0.001)$ & $-0.08(0.033)$ & $-0.09(0.003)$ & - \\
\hline Other & 0 & 0 & 0 & - \\
\hline
\end{tabular}


Table 3 Decomposition of the effect of POS cigarette marketing on SID

\begin{tabular}{lll}
\hline & $\beta$ & $p$-value \\
\hline Total effect & 0.31 & $<0.001$ \\
Direct effect & 0.25 & $<0.001$ \\
Total indirect & 0.06 & $<0.001$ \\
Indirect effects & & \\
$\quad$ via cravings, urges to buy, unplanned purchases & 0.01 & 0.001 \\
via cravings, unplanned purchases & 0.04 & $<0.001$ \\
via urges to buy, unplanned purchases & 0.01 & 0.03 \\
\hline
\end{tabular}

not being able to quit because of the stress associated with financial deprivation [44]. Our finding that POS cigarette marketing is associated with SID indicates that POS cigarette marketing can further exacerbate this vicious cycle.

Due to the cross-sectional nature of this study, its findings cannot be used to establish causality. While we controlled for several important predictors of SID in the analyses and used structural equation modelling with suggested directions of causality, our analysis was correlational and in the absence of a controlled experimental study, we are unable to make strong conclusions about causality.

A weakness of the measurement of many of our central constructs was that it relied on respondents' recollection of past events and behaviors. In particular, we measured SID by asking respondents to recall whether "in the past six months" they spent money on cigarettes that "resulted in not having enough money for household essentials". In addition to the issue of the difficulty recalling past events, the wording of our question might have led some respondents to confirm that smoking would result in financial deprivation.

\section{Conclusion}

With the passage of the Family Smoking Prevention and Tobacco Control Act in 2009, the Food and Drug Administration in the US gained the authority to regulate the marketing of tobacco products. Studies such as ours, suggesting that a reduction in cigarette marketing might improve the standards of living of smokers, can strengthen the evidence base needed by the FDA to ban all forms of POS cigarette marketing, as is the case in countries such as Australia, Canada, Croatia, Finland, Iceland, New Zealand, Norway, Russia, Thailand, and the UK.

\section{Ethical approval statement}

Institutional Review Board at University of Nebraska Medical Center provided the ethical approval for this study.

\section{Availability of data and materials}

De-identified, limited data will be shared by the lead author upon request.

\section{Abbreviations}

BRFSS: behavioral risk factor surveillance system; CFI: comparative fit index; HSI: heaviness of smoking index; POS: point of sale; RMSEA: root mean square error of approximation; SID: smoking induced deprivation; SEM: structural equation modelling; SD: standard deviation; TLI: tucker-lewis index.

\section{Competing interest}

All authors declare that there was no financial relationships with any organizations that might have an interest in the submitted work, neither did we have other relationships or activities that could appear to have influenced the submitted work.

\section{Authors' contributions}

MS designed the study, conducted the statistical analyses and wrote the manuscript. RAS assisted with the study design, reviewed the statistical analysis and interpretation of results, and participated in the drafting of the manuscript. RR, MT and GKS helped to conceptualize the study's research question, reviewed the interpretation of results and participated in the drafting of the manuscript. ASK assisted with the study design, reviewed the interpretation of results and participated in the drafting of the manuscript. GS and MM reviewed the statistical analysis and interpretation of results, and participated in the drafting of the manuscript. All authors read and approved the final manuscript.

\section{Acknowledgments}

We would like to thank all the authors contributing to this paper. Special thanks go to the approximately 1000 participants in the study who gave their time to answer our questions.

This work was funded through the National Institute of Health $(\mathrm{NIH})$ Grant \# R01CA166156. NIH was not involved in design of the study, in the collection, analysis, and interpretation of data; in the writing of the manuscript; and in the decision to submit the manuscript for publication.

\section{Author details}

'University of Nebraska Medical Center, 984365 Nebraska Medical Center, Omaha, NE 68198-4365, USA. ${ }^{2}$ University of Nebraska Omaha, 6001 Dodge St, Omaha, NE 68182, USA. ${ }^{3}$ The Center for Global Health and Health Policy, Global Health and Education Projects, P O Box 234, Riverdale, MD 20738, USA.

Received: 16 April 2015 Accepted: 29 March 2016

Published online: 28 April 2016

\section{References}

1. Wakefield MA, Terry-McElrath YM, Chaloupka FJ, Barker DC, Slater SJ, Clark $\mathrm{PI}$, Giovino GA. Tobacco industry marketing at point of purchase after the 1998 MSA billboard advertising ban. Am J Public Health. 2002;92(6):937-40.

2. Lavack AM, Toth G. Tobacco point-of-purchase promotion: examining tobacco industry documents. Tob Control. 2006;15(5):377-84.

3. Loomis BR, Farrelly MC, Mann NH. The association of retail promotions for cigarettes with the Master Settlement Agreement, tobacco control programmes and cigarette excise taxes. Tob Control. 2006;15(6):458-63.

4. Federal Trade Commission. Federal Trade Commission cigarette report for 2011. Washington DC: Federal Trade Commission; 2013.

5. Kim AE, Nonnemaker JM, Loomis BR, Shafer PR, Shaikh A, Hill E, Holloway JW, Farrelly MC. Influence of Point-of-Sale Tobacco Displays and Graphic Health Warning Signs on Adults: Evidence From a Virtual Store Experimental Study. Am J Public Health. 2014;104(5):888-95.

6. Carter BL, Robinson JD, Lam CY, Wetter DW, Tsan JY, Day SX, Cinciripini PM. A psychometric evaluation of cigarette stimuli used in a cue reactivity study. Nicotine Tob Res. 2006;8(3):361-9.

7. Hoek J, Gifford H, Pirikahu G, Thomson G, Edwards R. How do tobacco retail displays affect cessation attempts? Findings from a qualitative study. Tob Control. 2010;19(4):334-7.

8. Wakefield $M$, Germain $D$, Henriksen $L$. The effect of retail cigarette pack displays on impulse purchase. Addiction. 2008;103(2):322-8. 
9. Carter OB, Mills BW, Donovan RJ. The effect of retail cigarette pack displays on unplanned purchases: results from immediate postpurchase interviews. Tob Control. 2009;18(3):218-21.

10. Carter OB, Phan T, Mills BW. Impact of a point-of-sale tobacco display ban on smokers' spontaneous purchases: comparisons from postpurchase interviews before and after the ban in Western Australia. Tob Control. 2013; 0:1-6. doi:10.1136/tobaccocontrol-2013-050991.

11. Clattenburg EJ, Elf $J$, Apelberg BJ. Unplanned cigarette purchases and tobacco point of sale advertising: a potential barrier to smoking cessation. Tob Control. 2013;22(6):376-81.

12. Li L, Borland R, Fong GT, Thrasher JF, Hammond D, Cummings KM. Impact of point-of-sale tobacco display bans: findings from the International Tobacco Control Four Country Survey. Health Educ Res. 2013;28(5):898-910.

13. Siahpush M, Shaikh RA, Hyland A, Smith D, Kessler AS, Meza J, Wan N, Wakefield M: Point-of-Sale Cigarette Marketing, Urge to Buy Cigarettes, and Impulse Purchases of Cigarettes: Results From a Population-Based Survey. Nicotine Tob Res 2015. [Epub ahead of print].

14. Siahpush M, Shaikh RA, Cummings KM, Hyland A, Dodd M, Carlson L, Kessler AS, Meza J, Wan N, Wakefield M: The association of point-of-sale cigarette marketing with cravings to smoke: results from a cross-sectional populationbased study. Tob Control 2015. doi: 10.1136/tobaccocontrol-2015-052253.

15. Muruganantham G, Bhakat RS. A review of impulse buying behavior. Int J Mark Stud. 2013:5(3):149.

16. Kacen JJ, Hess JD, Walker D. Spontaneous selection: The influence of product and retailing factors on consumer impulse purchases. J Retail Consum Serv. 2012;19(6):578-88.

17. Siahpush M, Thrasher JF, Yong HH, Cummings KM, Fong GT, de Miera BS, Borland R. Cigarette prices, cigarette expenditure and smoking-induced deprivation: findings from the International Tobacco Control Mexico survey. Tob Control. 2013;22(4):223-6.

18. Siahpush M, Borland R, Scollo M. Smoking and financial stress. Tob Control. 2003;12:60-6.

19. Siahpush M, Borland R, Scollo M. Is household smoking status associated with expenditure on food at restaurants, alcohol, gambling and insurance? Results from the 1998-99 Household Expenditure Survey, Australia. Tob Control. 2004:13:409-14.

20. Siahpush M. Smoking and social inequality. Aust N Z J Public Health. 2004; 28(3):297-7.

21. Siahpush M, Borland R, YONG HH, Cummings KM, Fong GT. Tobacco expenditure, smoking-induced deprivation and financial stress: Results from the International Tobacco Control (ITC) Four-Country Survey. Drug Alcohol Rev. 2012;31(5):664-71

22. Yao $T$, Huang J, Sung H-Y, Ong MK, Mao Z, Jiang Y, Fong GT, Max W: Determinants of smoking-induced deprivation in China. Tobacco control. 2014:0:1-5. doi:10.1136/tobaccocontrol-2014-051542.

23. Adult Tobacco Use Information: Glossary [http://www.cdc.gov/nchs/nhis/ tobacco/tobacco_glossary.htm]. 3 Mar 2015.

24. Reitzel LR, Costello TJ, Mazas CA, Vidrine Jl, Businelle MS, Kendzor DE, Li Y, Cofta-Woerpel L, Wetter DW. Low-level smoking among Spanish-speaking Latino smokers: Relationships with demographics, tobacco dependence, withdrawal, and cessation. Nicotine Tob Res. 2009;11(2).

25. Shiffman S, Paty JA, Gnys M, Kassel JD, Elash C. Nicotine withdrawal in chippers and regular smokers: subjective and cognitive effects. Health Psychol. 1995;14(4):301.

26. Shiffman S, Paty J. Smoking patterns and dependence: contrasting chippers and heavy smokers. J Abnorm Psychol. 2006;115(3):509.

27. Centers for Disease Control and Prevention. SMART: BRFSS City and County Data. In: vol. 2015. Atlanta: Centers for Disease Control and Prevention; 2013.

28. Germain D, McCarthy M, Wakefield M. Smoker sensitivity to retail tobacco displays and quitting: a cohort study. Addiction. 2009;105(1):159-163.

29. Lochbuehler K, Engels RCME, Scholte RHJ. Influence of smoking cues in movies on craving among smokers. Addiction. 2009;104(12):2102-9.

30. Perkins KA, Jacobs L, Ciccocioppo M, Conklin C, Sayette M, Caggiula A. The influence of instructions and nicotine dose on the subjective and reinforcing effects of smoking. Exp Clin Psychopharmacol. 2004;12(2):91.

31. Conklin CA, Robin N, Perkins KA, Salkeld RP, McClernon FJ. Proximal versus distal cues to smoke: The effects of environments on smokers' cuereactivity. Exp Clin Psychopharmacol. 2008;16(3):207.

32. Warthen MW, Tiffany ST. Evaluation of cue reactivity in the natural environment of smokers using ecological momentary assessment. Exp Clin Psychopharmacol. 2009;17(2):70.
33. Bryant J, Bonevski B, Paul C. A survey of smoking prevalence and interest in quitting among social and community service organisation clients in Australia: a unique opportunity for reaching the disadvantaged. BMC Public Health. 2011;11(1):827.

34. Kozlowski L, Porter CQ, Orleans CT, Pope MA, Heatherton TF. Predicting smoking cessation with self-reported measures of nicotine dependence: FTQ, FTND, and HSI. Drug Alcohol Depend. 1994;34:211-6.

35. Heatherton TF, Kozlowski L, Frecker RC, Rickert W, Robinson J. Measuring the heaviness of smoking: using self-reported time to the first cigarette of the day and number of cigarettes smoked per day. Br J Addict. 1989;84:791-9.

36. StataCorp. Stata Statistical Software: Release 13, Special Edition. College Station, TX: StataCorp LP; 2013

37. Muthen LK, Muthen BO. Mplus User's Guide. Seventh Edition. Los Angeles, CA: Muthen \& Muthen; 2013

38. Acock AC: Discovering structural equation modeling using Stata. College Station, TX: Stata Press books; 2013.

39. Schreiber JB, Nora A, Stage FK, Barlow EA, King J. Reporting structural equation modeling and confirmatory factor analysis results: A review. J Educ Res. 2006;99(6):323-38.

40. Hu L, Bentler PM. Cutoff criteria for fit indexes in covariance structure analysis: Conventional criteria versus new alternatives. Struct Equation Model Multidiscip J. 1999:6(1):1-55.

41. Hooper D, Coughlan J, Mullen MR. Structural equation modelling: guidelines for determining model fit. J Bus Res. 2008;6(1):53-60.

42. Grace JB, Bollen KA. Interpreting the results from multiple regression and structural equation models. Bull Ecol Soc Am. 2005;86(4):283-95.

43. Siahpush M, Borland $\mathrm{R}$, Yong HH. Sociodemographic and psychosocial correlates of smoking-induced deprivation and its effect on quitting: findings from the International Tobacco Control Policy Evaluation Survey. Tob Control. 2007;16(2):e2.

44. Siahpush M, Yong HH, Borland R, Reid JL, Hammond D. Smokers with financial stress are more likely to want to quit but less likely to try or succeed: findings from the International Tobacco Control (ITC) Four Country Survey. Addiction. 2009;104(8):1382-90.

45. Siahpush M, Carlin JB. Financial stress, smoking cessation and relapse: results from a prospective study of an Australian national sample. Addiction. 2006; 110:121-7.

46. Kendzor DE, Businelle MS, Costello TJ, Castro Y, Reitzel LR, Cofta-Woerpel LM, Li Y, Mazas CA, Vidrine Jl, Cinciripini PM et al. Financial strain and smoking cessation among racially/ethnically diverse smokers. Am J Public Health. 2010;100(4):702-6.

\section{Submit your next manuscript to BioMed Central and we will help you at every step:}

- We accept pre-submission inquiries

- Our selector tool helps you to find the most relevant journal

- We provide round the clock customer support

- Convenient online submission

- Thorough peer review

- Inclusion in PubMed and all major indexing services

- Maximum visibility for your research

Submit your manuscript at www.biomedcentral.com/submit
) Biomed Central 